\title{
Initiation of Germination of Bacterial Spores by Hydrostatic Pressure
}

\author{
By G. W. GOULD AND A. J. H. SALE \\ Unilever Research Colworth/Welwyn Laboratory, Colworth House, Sharnbrook, Bedford
}

(Accepted for publication 12 November 1969)

SUMMARY

Hydrostatic pressure initiated germination of bacterial spores in nutrientfree media. Those spores which were most dormant towards chemical germinants at I atmosphere pressure were also the most resistant to germination by pressure treatment. Germination by high pressure treatment was characterized by temperature and $\mathrm{pH}$ optima, like germination at atmospheric pressure. Germination initiated by pressure was inhibited by metabolic poisons and was potentiated by low concentrations of various nutrients including some of those which are normally germinative (at higher concentrations) at atmospheric pressure. In particular, L-alanine and closely related $\alpha$-amino acids, but not their breakdown products, potentiated germination initiated by pressure. Study of potentiation by D-alanine (which strongly inhibits germination initiated by L-alanine at I atmosphere pressure) revealed that high pressures caused an increase in the rate of racemization of alanine by spores. Germination by pressure probably resulted from acceleration of some germination reaction which is normally negligibly slow at a pressure of I atmosphere, and also from an increase in permeability of some barrier within the spore to L-alanine and related $\alpha$-amino acids.

\section{INTRODUCTION}

Inactivation of bacterial spores by hydrostatic pressures, unlike the inactivation of vegetative bacteria, occurred in two stages (Clouston \& Wills, 1969; Sale, Gould \& Hamilton, 1970). First, pressure caused germination of the spores, and then it inactivated the germinated forms. However, pressures of only a few hundred atmospheres could still cause germination, but were too low to inactivate the resulting germinated forms. The overall effect of such pressures was therefore solely to cause germination, i.e. heat-sensitization of the spores, optical, structural and chemical changes which normally occur during germination. Study of environmental factors showed that pressure inactivation of spores was strongly influenced by temperature, and less strongly by $\mathrm{pH}$ value, water activity and ionic strength.

Pressure germination is of interest as a potential step in preservation procedures aimed at eliminating spores from perishable materials. It is also worth studying as a novel initiator of germination, because the way in which spore germination is initiated by any germinant system is not yet understood.

Germination and inactivation of spores of Bacillus pumilis by pressures up to 1700 atmospheres (atm.) was originally described by Clouston \& Wills (1969). The present paper is concerned with the germinant action of hydrostatic pressure on spores of 
various Bacillus and Clostridium species, and in particular describes the strongly synergistic effect of pressure with some of the more often studied 'physiological' germinants. The pressure range was limited to $1000 \mathrm{~atm}$. when we found that the synergistic effect disappeared at higher pressures.

\section{METHODS}

Organisms and production of spores. Bacillus subtilis MARBURG ATCC605I, B. brevis NCTC 7577 and $B$. pumilis S 3 (laboratory isolate) were grown at $37^{\circ}$ on the surface of potato, glucose, yeast-extract agar. Procedures for recovery and 'cleaning' of spores were as described previously (Sale et al. 1970). Suspensions were stored at $4^{\circ}$, in water, and were activated by heating $\left(70^{\circ}, 30 \mathrm{~min}\right.$.) before use unless stated otherwise in Results.

Pressure treatment. Preparation of samples and the method of application of pressure were as described by Sale et al. (1970). Pressures up to 600 atm. were generated directly by an electrically driven hydraulic pump connected by a pipe to the vessel in which the sample sachets were treated. The vessel was immersed in a water bath for control of temperature. The pressure was measured by a Bourdon tube pressure gauge.

Measurement of germination. Spores for germination studies were suspended at a concentration of about $10^{8} / \mathrm{ml}$. in $\mathrm{O} \cdot \mathrm{I}$ M-sodium phosphate buffer $(\mathrm{pH} 8.0$ ) unless stated otherwise in Results. Germination was measured in three ways. (I) The optical density (O.D.) of suspensions was measured using an absorptiometer ('Biochem'; Hilger \& Watts Ltd., Camden Road, London), fitted with a $580 \mathrm{~m} \mu$ peak transmission filter; germination was accompanied by a fall in o.D. (2) Samples were examined microscopically using phase contrast optics, when ungerminated spores appeared bright and germinated spores appeared dark. About 250 spores were examined from each sample and the percentage germination recorded. These two methods were insensitive when the amount of germination exceeded $98 \%$ or so, in which case the third method was used. (3) Samples ( $\mathrm{I} \mathrm{ml}$.) were sealed in thin walled glass ampoules which were heated by total immersion in a water bath at $70^{\circ}$ for $30 \mathrm{~min}$. The surviving heat-resistant (i.e. ungerminated) spores were then enumerated by poured plate viable counts using nutrient agar (Oxoid).

Chemicals. Amino acids, nucleosides and related compounds were obtained from British Drug Houses l_td. (Poole, Dorset) or Koch-Light Laboratories Ltd. (Colnbrook, Bucks.). $O$-Carbamyl-D-serine was a gift from Dr P. H. Hidy (Commercial Solvents Corp., Terre Haute, Indiana). Other chemicals were of Analar grade.

Alanine racemase. Racemization of alanine by whole spores was measured in the direction $\mathrm{L} \rightarrow \mathrm{D}$ by the method of Yoshimoto (1958) using D-amino acid oxidase (British Drug Houses Ltd.; Wood \& Gunsalus, 195I) as described by Jones \& Gould (1968).

\section{RESULTS}

\section{Initiation of germination by pressure: optimum temperature and pressure}

The optimum temperature for initiation of spore germination differed at different pressures. As the pressure was increased, the optimum temperature for germination, as measured by phase-darkening of spores or by viable counts of heat-resistant survivors, increased also. This trend is shown in Fig. I for spores of Bacillus coagulans, $B$. subtilis and B. cereus. 
Germination was minimal at low temperatures whatever the pressure, but at high pressures germination occurred at temperatures well above those that supported germination at $r$ atm. pressure (e.g. at $60^{\circ}$ and $70^{\circ}$ ).

In general, those spores most dormant towards nutrient germinants at I atm. were

(a)

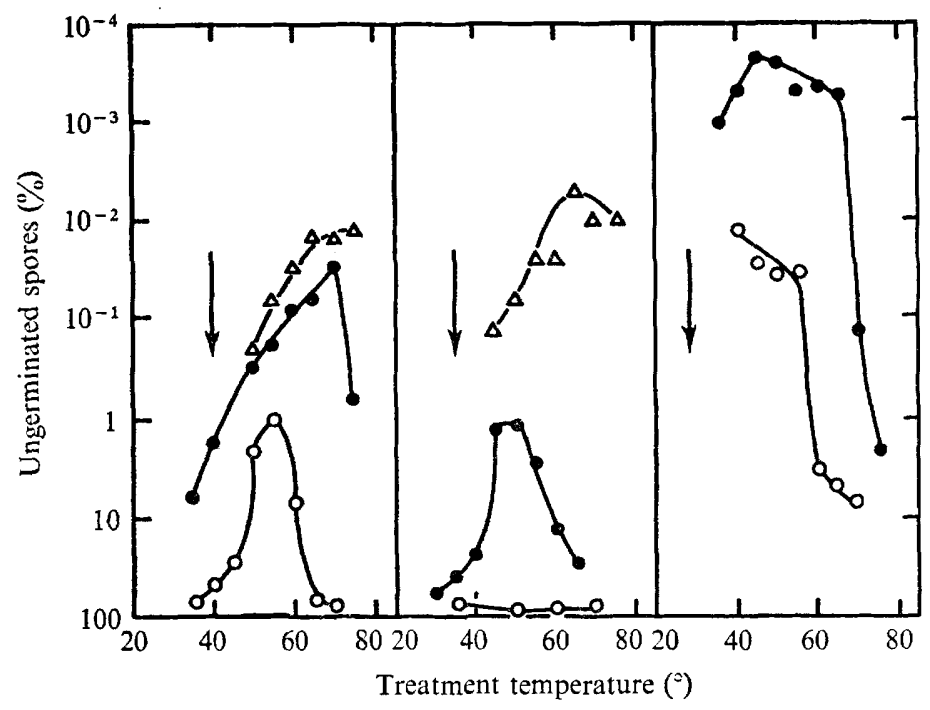

Fig. I. Pressure germination at different temperatures. Spores of Bacillus coagulans $(a), B$. subtilis var. niger (syn. globigii) (b) and B. cereus $\mathrm{T}\left(\right.$ c) were heat activated at $70^{\circ}$ for 30 min., then suspended in $\mathrm{O}^{\circ} \mathrm{I} \mathrm{M}$-sodium phosphate $(\mathrm{pH} \mathrm{8.0)}$ and subjected to pressures of $250 \mathrm{~atm}$. $(O), 500 \mathrm{~atm}$. (๑) and $1000 \mathrm{~atm}$. ( $\triangle$ ) for $30 \mathrm{~min}$. periods. The germination was measured by heating samples $\left(70^{\circ}, 30 \mathrm{~min}\right.$.) to kill germinated forms and estimating the numbers of ungerminated survivors by viable counting. The vertical arrows indicate the temperature optima for germination of these spores by L-alanine at $\mathbf{I}$ atm. pressure.

Table I. Increase in pressure germination of heat-activated spores

Organism

Bacillus cereus $\mathbf{T}$

\section{Pressure (atm.)}

250
500

IOOO

\section{B. subtilis MARBURG}

B. brevis

B. coagulans

B. subtilis var. niger (syn. globigii)

$B$. pumilis $\$ 3$

$\overbrace{\begin{array}{c}\text { Unactivated } \\ \text { spores }\end{array}}^{\text {Germination }(\%)^{*}} \underbrace{*}_{\begin{array}{c}\text { Activated } \\ \text { spores }\end{array}}$

\begin{tabular}{rr}
60 & 95 \\
- & 10 \\
75 & 50 \\
20 & 99 \\
$>99$ & 40 \\
30 & $>99$ \\
0 & 60 \\
20 & 99 \\
60 & 80 \\
80 & 90 \\
\hline 0
\end{tabular}

* Incubation temperature was $25^{\circ}$. Spores were suspended in 0.1 M-sodium phosphate $(\mathrm{pH} 8 \cdot 0)$. Germination was estimated by counting the percentage of phase-dark spores: incubated but not pressurized controls were all less than $5 \%$ phase-dark.

+ Activation was at $70^{\circ}$ for $30 \mathrm{~min}$. 
also most dormant towards pressure (e.g. Bacillus coagulans and B. subtilis var. niger (syn. globigii) in Fig. I $a, b$, compared with the less dormant spores of $B$. cereus $\mathrm{T}$ in Fig. I $c$ ).

\section{Stimulation of pressure germination by heat activation}

Heat-activated spores were germinated more completely by pressure than were unheated spores (Table 1). However, germination initiated at higher pressures, i.e. above about 1000 atm., was much less influenced by activation than germination initiated at lower pressures.

\section{Influence of $\mathrm{pH}$ value on pressure germination}

Pressure initiated the germination of spores optimally near neutral $\mathrm{pH}$, but the optimum was much broader than for germination of spores initiated by nutrients at I atm. pressure (Fig. 2).

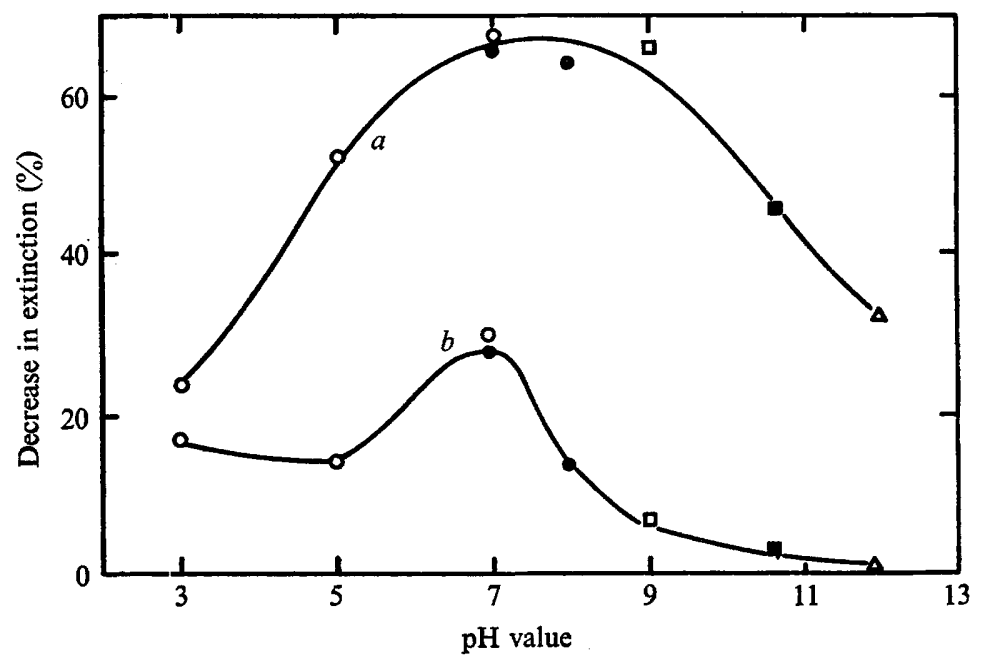

Fig. 2. Pressure germination at different $\mathrm{pH}$ values. Spores of Bacillus cereus $\mathrm{T}$ were activated at $70^{\circ}$ for $30 \mathrm{~min}$., then suspended in the following buffers $\left(\mathrm{O}^{\circ} \mathrm{I} \mathrm{M}\right)$ and subjected to pressures of $1000 \mathrm{~atm}$. (curve $a$ ) or $250 \mathrm{~atm}$. (curve $b$ ) for $30 \mathrm{~min}$. at $25^{\circ}:$ sodium citrate/phosphate $(O)$; sodium phosphate $(\bullet)$; tris (hydroxymethylaminomethane) $/ \mathrm{HCl}(\square)$; sodium bicarbonate/ carbonate $(\boldsymbol{\square})$; sodium carbonate/hydroxide $(\triangle)$. Germination was estimated by measuring the fall in extinctior of the treated samples.

\section{Effect of anaerobiosis on pressure germination of aerobic spores}

Spores of Bacillus coagulans could be germinated by pressure as effectively in media containing reducing agents as in aerobic media (Table 2). Germination of spores of aerobes by nutrients at I atm. is well known to be similarly unaffected by anaerobiosis.

\section{Stimulation of pressure germination by amino acids and other compounds}

Germination initiated by the lower pressures (below about rooo atm.) was markedly affected by constituents of the suspending medium (see, for example, the effect of alanine in Table 3). The influence of alanine decreased with rising pressure and became negligible between 1000 and 2000 atm. Following the observations that germination 
at such high pressures was in general relatively unaffected by changes of environment or pretreatment of the spores, the experimental pressure range was restricted to I000 atm. maximum.

Of a variety of substances tested, amino acids were clearly the most effective potentiators of pressure germination. For example, inspection of the results summarized in

\section{Table 2. Pressure germination of Bacillus coagulans spores in aerobic and anaerobic media}

\begin{tabular}{|c|c|c|}
\hline & $\begin{array}{r}\text { Ungerminated } \\
\text { press }\end{array}$ & $\begin{array}{l}(\%) \text { following } \\
n^{*} \text { at }\end{array}$ \\
\hline Medium & $2000 \mathrm{~atm}$ & $3000 \mathrm{~atm}$. \\
\hline $\begin{array}{l}\text { Aerobic } \\
\text { Water } \\
\text { Buffer } \dagger \\
\text { Yeast glucose broth }\end{array}$ & $\begin{array}{l}1 \cdot 7 \times 10^{-4} \\
1 \cdot 2 \times 10^{-4}\end{array}$ & $1 \cdot 2 \times 10^{-3}$ \\
\hline $\begin{array}{l}\text { Anaerobic } \\
\text { Buffer plus thioglycollate } \dagger \\
\text { R C M } \ddagger\end{array}$ & $\mathrm{I} \cdot 3 \times 10^{-4}$ & $1.0 \times 10^{-3}$ \\
\hline
\end{tabular}

* Pressurization was for $30 \mathrm{~min}$. at $70^{\circ}$. Ungerminated spores were estimated by viable counts. $\dagger$ Buffer was $0 \cdot 1 \mathrm{M}$-sodium phosphate $(\mathrm{pH} \mathrm{8 \cdot 0)}$; sodium thioglycollate was used at $0 \cdot 1 \%(\mathrm{w} / \mathrm{v})$. $\ddagger$ Reinforced Clostridium medium (Gibbs \& Hirsch, 1956).

Table 3. Initiation of spore germination by pressure at different temperatures

\begin{tabular}{|c|c|c|c|c|c|c|c|c|}
\hline \multirow[b]{2}{*}{ Organism } & \multirow[b]{2}{*}{ Addition $\ddagger$} & \multicolumn{7}{|c|}{ Germination $(\%) *$ after pressurization $\dagger$ at } \\
\hline & & $0^{\circ}$ & $20^{\circ}$ & $30^{\circ}$ & $40^{\circ}$ & $50^{\circ}$ & $60^{\circ}$ & $70^{\circ}$ \\
\hline \multirow[t]{3}{*}{ Bacillus coagulans } & None & 0 & 0 & $\mathbf{I}$ & 0 & 50 & 60 & 0 \\
\hline & L-Alanine $(250 \mu \mathrm{M})$ & 0 & 0 & 5 & $>95$ & $>95$ & $>95$ & 50 \\
\hline & L-Alanine (I mM) & o & 0 & 12 & $>95$ & $>95$ & $>95$ & 50 \\
\hline \multirow{3}{*}{$\begin{array}{l}\text { B. subtilis var. niger (syn. } \\
\text { globigii) }\end{array}$} & None & I & 1 & 2 & 3 & IO & Io & 8 \\
\hline & L-Alanine $(250 \mu \mathrm{M})$ & I & I & 50 & 50 & 75 & 30 & 25 \\
\hline & L-Alanine ( $\mathrm{r} \mathrm{mm})$ & I & I & 68 & $>90$ & 70 & 36 & 13 \\
\hline \multirow[t]{2}{*}{ B. cereus $\mathrm{T}$} & None & 0 & 0 & 2 I & 40 & 64 & 5 & - \\
\hline & L-Alanine $(250 \mu \mathrm{M})$ & 12 & $>95$ & $>99$ & $>99$ & $>99$ & $>99$ & 95 \\
\hline
\end{tabular}

* Spores were activated $\left(70^{\circ}, 30 \mathrm{~min}\right.$.) before use; germination was measured by recording the percentage of phase-dark spores.

$\dagger$ Pressure was $250 \mathrm{~atm}$. maintained for $30 \mathrm{~min}$.

\$ Suspending medium was $0 \cdot \mathrm{I}$ M-sodium phosphate $(\mathrm{pH} 8 \cdot 0)$.

Table 4 indicated that spores of Bacillus cereus could be caused to germinate at I atm. by a variety of amino acids, particularly at the higher concentration used (IO $\mathrm{mM}$ ) and in the presence of inosine. Germination of $\boldsymbol{B}$. cereus spores caused by pressure was similarly potentiated by a variety of amino acids. In contrast, spores of $B$. coagulans were much less responsive than those of $B$. cereus to amino acids at I atm., germinating rapidly only in $\mathrm{L}$-alanine, and much less rapidly in $\mathrm{L}-\alpha$-aminobutyric acid and L-valine; similarly, the range of amino acids potentiating germination at $200 \mathrm{~atm}$. pressure was much more restricted than the range potentiating germination of spores of $B$. cereus. Amino acids were effective germinants at $200 \mathrm{~atm}$. at concentrations well below those effective at I atm. 
In general the amino acids most effective in potentiating germination by pressure were those which were also most effective as germinants, either alone or with inosine, at I atm. However, there were exceptions to this generalization, e.g. L-serine was not germinative in any of the systems tested at $\mathbf{I}$ atm. and yet strongly potentiated germination of spores of Bacillus cereus at 200 atm., and L-leucine, L-isoleucine and L-aspartic

Table 4. Potentiation of pressure germination of spores by amino acids



acid were less effective at $200 \mathrm{~atm}$. than one would expect from their potentiation, with inosine, of germination at $\mathrm{I}$ atm.

Only in the case of alanine was the D-isomer about as effective as the L-isomer in potentiating pressure germination. Other D-isomers were relatively ineffective, even when the corresponding L-isomers were strong potentiators (e.g. cysteine, phenylalanine). 


\section{Role of alanine racemase in pressure germination}

The anomalous situation, that D-alanine (which inhibits germination at I atm.) potentiated pressure germination, suggested that pressure might cause racemization to the L-form. This was so (Fig. 3). Consequently, under pressure there was a rapid formation of L-alanine (which stimulated germination) from the inhibitory D-enantiomorph. Furthermore, rate studies showed that pressure germination was in fact initially

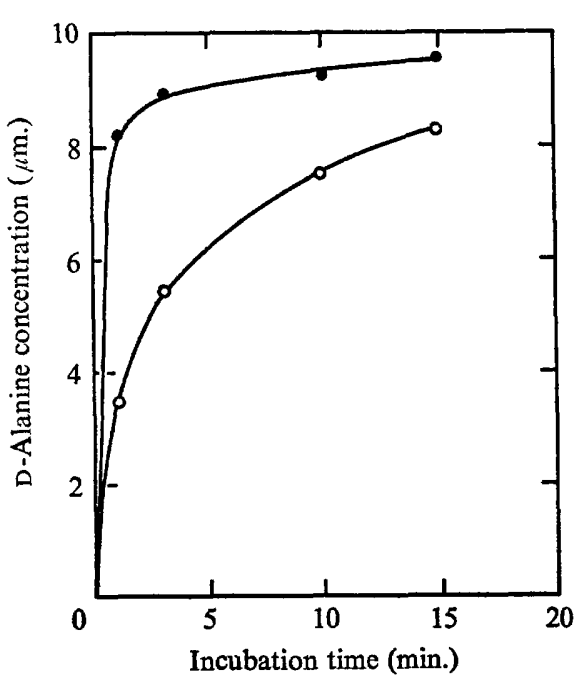

Fig. 3

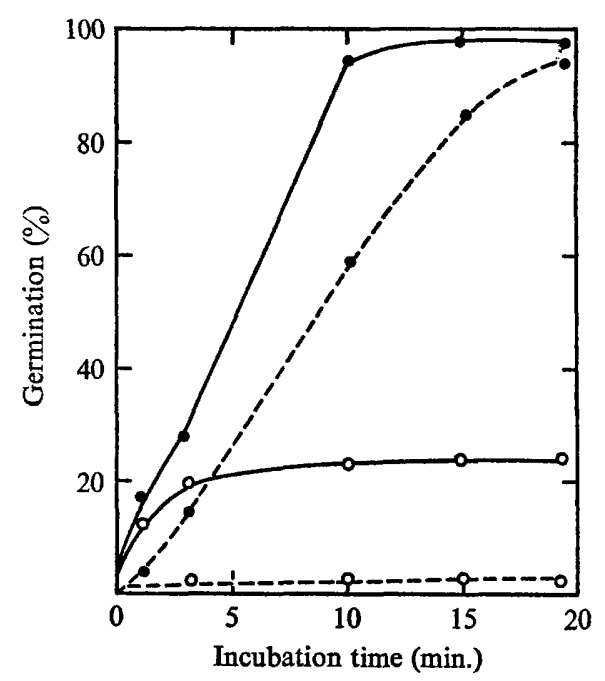

Fig. 4

Fig. 3. Racemization of alanine under pressure. Spores of Bacillus cereus $\mathrm{T}$ were incubated $\left(25^{\circ}\right)$ with L-alanine $(25 \mu \mathrm{M})$ in sodium phosphate $(0 . \mathrm{I} \mathrm{M}, \mathrm{pH} 8 \cdot 0)$ at $\mathrm{I}$ atm. (O) or $250 \mathrm{~atm}$. ( $)$ pressure. Samples were assayed for racemization by measuring formation of $\mathrm{D}$-alanine as described in Methods.

Fig. 4. Germination of spores in L- and D-alanine. Spores of B. cereus $\mathrm{T}$ were incubated $\left(25^{\circ}\right)$ in $\mathrm{O} \cdot \mathrm{I}$ M-sodium phosphate $(\mathrm{pH} 8 \cdot 0$ ) containing $250 \mu \mathrm{M}$ of $\mathrm{L}$-alanine (continuous lines) or $D$-alanine (dashed lines) at $\mathrm{I}$ atm. (O) or $250 \mathrm{~atm}$. (๑) pressure. Samples were assayed for germination by determining the percentage of spores which had become phase-dark.

potentiated more rapidly by L- than by D-alanine, although the difference was small after the first few minutes of pressurization (Fig. 4). The hypothesis that D-alanine potentiated pressure germination via formation of $\mathrm{L}$-alanine was further substantiated by using an inhibitor of alanine racemase, $O$-carbamyl-D-serine (OCDS). This substance strongly antagonized the potentiating action of $\mathrm{D}$-alanine (presumably by arresting racemization to L-alanine), whilst increasing the potentiating action of L-alanine (presumably by arresting racemization to D-alanine) (Table 5). Interestingly, with the exception of phenylalanine, OCDS had little effect on the potentiation of pressure germination by other amino acids, suggesting that alanine was not involved as an intermediate in these instances (Table 5).

\section{Stimulation of pressure germination by ribosides and related compounds}

Ribosides, which are strong potentiators of the germination of spores of certain species initiated by amino acids at I atm., were much less effective than amino acids 
as potentiators of germination under pressure (Table 6). Of the ribosides tested inosine (which is the most effective riboside germinant at $\mathrm{I}$ atm.) most strongly potentiated the germination of spores of Bacillus cereus caused by pressure. Of the other ribosides, adenosine, guanosine and deoxyinosine caused weak potentiation; these three were also weakly active as germinants at I atm. (i.e. when used at higher concentrations than in Table 6).

The ribosides, which do not germinate Bacillus coagulans spores at I atm., did not potentiate the germination by pressure either.

None of the possible metabolites tested, which could be formed more or less directly by breakdown of inosine or alanine, was a potentiator of germination caused by pressure.

\section{Table 5. Effect of $O$-carbamyl-D-serine $(O C D S)$ on the germination of spores of Bacillus cereus by pressure}

\begin{tabular}{|c|c|c|c|c|c|}
\hline \multirow[b]{3}{*}{ Amino acid $\S$} & \multirow[b]{3}{*}{ Concentration } & \multicolumn{4}{|c|}{ Germination $(\%)^{*}$ following incubation $\dagger$ in } \\
\hline & & \multicolumn{2}{|c|}{ Absence of OCDS } & \multicolumn{2}{|c|}{ Presence of OCDS } \\
\hline & & I atm. & $200 \mathrm{~atm}$. & I atm. & $200 \mathrm{~atm}$. \\
\hline Control (no addition) & & 0 & 0 & 0 & 0 \\
\hline \multirow[t]{2}{*}{ L-Alanine } & $50 \mu \mathrm{M}$ & 9 & 100 & $85 \cdot 5$ & 100 \\
\hline & $\mathrm{I} \mu \mathrm{M}$ & 0 & 7 & 0 & 100 \\
\hline \multirow[t]{2}{*}{ D-Alanine } & $50 \mu \mathrm{M}$ & 0 & 100 & 0 & 4 \\
\hline & Iо $\mu \mathrm{M}$ & 0 & 14 & 0 & 0 \\
\hline L-Phenylalanine & $50 \mu \mathrm{M}$ & 0 & $22 \cdot 5$ & 0 & $8 I \cdot 5$ \\
\hline$\beta$-Alanine & $250 \mu \mathrm{M}$ & 0 & 5 & 0 & $5 \cdot 5$ \\
\hline Glycine & $20 \mu \mathrm{M}$ & 0 & $7 \cdot 5$ & 0 & 8 \\
\hline L- $\alpha$-Aminobutyric acid & $10 \mu \mathrm{M}$ & o & $5 \cdot 5$ & 0 & 6 \\
\hline L-Cysteine & $500 \mu \mathrm{M}$ & o & 74 & 0 & 74 \\
\hline
\end{tabular}

* Spores were activated before use $\left(70^{\circ}, 30 \mathrm{~min}\right.$.); germination was measured by recording the percentage of phase-dark spores.

+ Spores were incubated at $30^{\circ}$ for $30 \mathrm{~min}$. in $0.1 \mathrm{M}$-sodium phosphate $(\mathrm{pH} 8.0)$ plus the indicated amino acids.

$\ddagger O$-Carbamyl-D-serine was used at a concentration of I00 $\mu \mathrm{M}$.

$\S$ In addition to those amino acids in the Table, OCDS did not influence the potentiation of pressure germination caused by L-tyrosine, L-serine, L-threonine or L-tryptophan.

\section{Inhibition of pressure germination}

In addition to low temperatures (Table 3) and extreme $\mathrm{pH}$ values (Fig. 2), pressure germination was inhibited by various metabolic poisons and antimetabolites known to inhibit germination at I atm. (Table 7). Further experiments showed that, just as the potentiators (e.g. amino acids, above) became less effective in accelerating germination, so the various inhibitors became less effective in preventing germination as the pressure employed was increased.

\section{DISCUSSION}

The fact that inhibitors of germination initiated by nutrients (octyl alcohol, mercuric chloride etc.; Table 7) also inhibited the germination initiated by pressure, suggested that pressure caused germination via some enzyme reaction(s) rather than by simple physical distortion of the spore (e.g. 'mechanical germination'; Rode \& Foster, 1960). 
Table 6. Potentiation of pressure germination of spores by ribosides, products of amino acid metabolism, and related compounds

\begin{tabular}{|c|c|c|c|c|c|c|}
\hline \multirow[b]{3}{*}{ Addition } & \multirow[b]{3}{*}{ Concentration } & \multicolumn{5}{|c|}{ Germination $(\%)^{*}$ following incubation $\dagger$} \\
\hline & & \multicolumn{2}{|c|}{ Bacillus cereus } & \multicolumn{3}{|c|}{ Bacillus coagulans } \\
\hline & & I atm. & $200 \mathrm{~atm}$. & I atm. & $200 \mathrm{~atm}$. & $400 \mathrm{~atm}$. \\
\hline Control (no addition) & & 0 & 0 & 0 & o & 27 \\
\hline L-Alanine & I $\mathrm{mM}$ & 25 & 100 & 40 & $92 \cdot 5$ & 94 \\
\hline & $100 \mu \mathrm{M}$ & I & 100 & II 5 & $8 \mathrm{I}$ & $92 \cdot 5$ \\
\hline Inosine & $1 \mathrm{~mm}$ & 100 & 100 & 0 & 3 & 27 \\
\hline & $\mathrm{I} 00 \mu \mathrm{M}$ & $8 \mathrm{I}$ & 100 & 0 & 0 & 27 \\
\hline & $30 \mu \mathrm{M}$ & I & 99 & n.t. & n.t. & n.t. $\ddagger$ \\
\hline & Io $\mu \mathrm{M}$ & 0 & $16 \cdot 5$ & 0 & o & 26 \\
\hline L-Alanine & $100 \mu \mathrm{M}$ & 87 & 100 & 13 & 82 & 95 \\
\hline plus inosine & $\mathrm{I} 0 \mu \mathrm{M} \quad\}$ & & & & & \\
\hline Deoxyinosine & $30 \mu \mathrm{M} \S$ & 0 & 4 & 0 & n.t. & 24 \\
\hline Adenosine & $30 \mu \mathrm{M} \S$ & o & 20 & o & n.t. & 26 \\
\hline Deoxyadenosine & $30 \mu \mathrm{M} \S$ & 0 & 0 & 0 & n.t. & $26 \cdot 5$ \\
\hline Guanosine & $30 \mu \mathrm{M} \S$ & 0 & 9 & 0 & n.t. & 26 \\
\hline Deoxyguanosine & $30 \mu \mathrm{M} \S$ & 0 & 0 & 0 & n.t. & $25 \cdot 5$ \\
\hline Xanthosine & $30 \mu \mathrm{M} \S$ & 0 & 0 & 0 & n.t. & 26 \\
\hline $\begin{array}{l}\text { Riboside } \\
\text { breakdown products } T\end{array}$ & $30 \mu \mathrm{M} \S$ & 0 & 0 & 0 & n.t. & $24-29$ \\
\hline $\begin{array}{l}\text { Amino acid } \\
\text { breakdown products }\end{array}$ & $30 \mu \mathrm{M} \S$ & 0 & 0 & 0 & 0 & n.t. \\
\hline
\end{tabular}

* Spores were activated before use $\left(70^{\circ}, 30 \mathrm{~min}\right.$.); germination was measured by recording the percentage of phase-dark spores.

$\dagger$ Spores were incubated for $30 \mathrm{~min}$. at $30^{\circ}$ (Bacillus cereus) or $40^{\circ}$ (B. coagulans) in O. I M-sodium phosphate $(\mathrm{pH} 8.0)$ plus the indicated additions.

$\$$ Not tested.

$\S$ Concentrations were $\mathrm{I} \mathrm{mm}$ for B. coagulans spores.

T The following riboside and amino acid breakdown products and related metabolites were inactive: hypoxanthine, D-ribose, D-ribose 5-phosphate, 3-phosphoglycerate, 2-phosphoglycerate, pyruvate, ammonium (sulphate), nicotinamide adenine dinucleotide and nicotinamide adenine dinucleotide phosphate (oxidized and reduced forms), formate, acetate, acetyl phosphate, acetyl coenzyme A, coenzyme A, citrate, succinate, phosphopyruvate, adenosine diphosphate and adenosine triphosphate.

Unlike pressure on gaseous systems, hydrostatic pressure of the magnitude used here causes little compression of the liquid (water is compressed less than $4 \%$ at $1000 \mathrm{~atm}$.) and therefore results in negligible changes in concentrations of solutes. Furthermore, the effectiveness of relatively low pressures (i.e. below I000 atm.) in causing germination of certain spores suggested that pressure was not acting by causing denaturation of proteins or other macromolecules: such changes characteristically become pronounced at pressures well in excess of 1000 atm., and particularly at elevated temperatures. In fact a high proportion of spores survived pressures as high as $8000 \mathrm{~atm}$. at room temperature (Sale et al. 1970). Laidler (195I) showed that at high temperatures the dominant effect of pressure on biological materials was on equilibria between natural and denatured forms of enzymes, whereas at lower temperatures the principal effect was on the rates of enzyme-substrate reactions. Pressures of the order of hundreds of atmospheres, at relatively low temperatures, usually affect the rates of reactions in which reactants and products have different molecular volumes.

Such an effect on a germination reaction which normally has a negligible rate at 


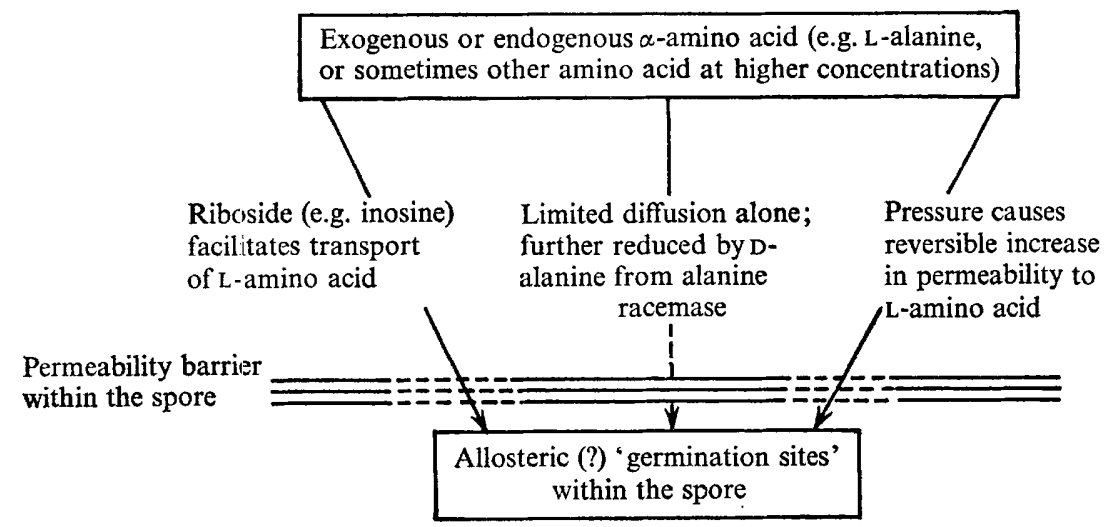

Fig. 5. Diagrammatic representation of the manner in which nutrient (e.g. riboside) or physical (e.g. pressure) potentiators of germination may increase the germinative action of L-alanine or other amino acids. The permeability barrier is regarded as a barrier within the spore, separating the 'germination sites' not only from exogenous but also from endogenous germinative amino acids.

Table 7. Inhibition of pressure germination of spores

\begin{tabular}{|c|c|c|c|}
\hline & & Germination $(\%)^{*}$ & llowing incubationt \\
\hline & & $\begin{array}{l}\text { Bacillus cereus } \\
\text { at } 400 \mathrm{~atm} .\end{array}$ & $\begin{array}{l}\text { Bacillus coagulans } \\
\text { at } 600 \text { atm. }\end{array}$ \\
\hline Addition & Concentration & & \\
\hline Control (no addition) & & 100 & 87 \\
\hline Ethyl pyruvate & I mM & 100 & 79 \\
\hline & $10 \mathrm{mM}$ & 100 & 0 \\
\hline W I435t & I mM & 100 & 4 \\
\hline & $10 \mathrm{~mm}$ & 100 & 0 \\
\hline Octyl alcohol & I mM & 53 & 24 \\
\hline & $10 \mathrm{~mm}$ & 0 & 0 \\
\hline Cupric sulphate & $\mathrm{I} \mathrm{mm}$ & 100 & 89 \\
\hline & $10 \mathrm{~mm}$ & $9 I$ & 85.5 \\
\hline Mercuric chloride & I $\mathrm{mM}$ & 0 & 0 \\
\hline & IO $\mathrm{mM}$ & o & 0 \\
\hline Iodoacetamide & $\mathrm{I} \mathrm{mm}$ & 95 & 88 \\
\hline & $10 \mathrm{~mm}$ & $84 \cdot 5$ & $89 \cdot 5$ \\
\hline
\end{tabular}

* Spores were activated before use $\left(70^{\circ}, 30 \mathrm{~min}.\right)$; germination was measured by recording the percentage of phase-dark spores.

$\dagger$ Spores were incubated for $30 \mathrm{~min}$. at $30^{\circ}$ (Bacillus cereus) or $40^{\circ}$ (B. coagulans) in 0.1 M-sodium phosphate $(\mathrm{pH} 8 \cdot 0)$ plus the inhibitors listed.

$\ddagger$ Bis- 1 : 3- $\beta$-ethylhexyl-5-methyl-5-aminohexahydropyridine; an antagonist of pyruvate metabolism.

I atm. could account for the germinative action of pressure, and also for the observed $\mathrm{pH}$ and temperature optima and the effects of metabolic inhibitors. Similar situations are known in biological systems other than spores. Hydrolysis of L-tyrosine ethyl ester by chymotrypsin (Werbin \& McLaren, I95I $a$ ) and of L-arginyl methyl ester by trypsin (Werbin \& McLaren, I95I $b$ ) was accelerated by pressure at moderate temperatures $\left(25^{\circ}\right.$ to $\left.55^{\circ}\right)$ : the rate of lysis of Micrococcus lysodeikticus by lysozyme was increased by moderate pressure (Douglas \& Johnson, 195I): in a more complex situation, high 
pressure $\left(6500 \mathrm{~atm}\right.$. at $\left.35^{\circ}\right)$ caused an increase in ATP levels in human amnion cells, presumably by stimulating some ATP-generating reaction(s) (Landau \& Peabody, 1963).

Nevertheless, the reduction in the degree of germination which occurred below about $40^{\circ}$ as the pressure was increased above the optimum of 4000 atm. (Sale et al. 1970) is less easily explained, unless one postulates that at these higher pressures the conformation of a critical germination enzyme was so changed as to inhibit reversibly the germination reaction.

An alternative explanation of pressure germination was suggested by the observation that pressure accelerated the racemization of alanine catalysed by spores (Fig. 3). Racemization of alanine does not involve a net change in molecular volume of reactants and products, therefore the reaction rate should not be affected by pressure solely by mass action. The observed acceleration by pressure must have some other cause: for instance, a conformational change in the racemase molecule, leading to more rapid action, or (since whole spores were used as the racemase in these experiments) some change in permeability of spores to the substrate alanine could have allowed more rapid racemization. Pressure has been shown to reduce the stereospecificity of an enzyme reaction, for example the hydrolysis of methyl esters of benzoyl L-and D-alanine by $\alpha$-chymotrypsin (Gonikberg, Prokhorova \& El'yanov, 1968). Major conformational changes are not likely below 1000 atm., thus it is more likely that the lower pressures acted by increasing the permeability of spores. The observed synergism of pressure with low levels of various amino acids can be explained on this basis, i.e. if pressure increased the permeability of spores to these germinative compounds.

Interestingly, pressure influenced the germination initiated by amino acids much more than by ribosides. If a permeability change is the correct explanation of pressure germination, it follows that germination at I atm. is normally severely restricted by the low permeability of spores to the germinative $\alpha$-amino acid, which seems to be an essential endogenous germinant even for those spores which may be caused to germinate by addition of ribosides alone (Black \& Gerhardt, 196I; Warren \& Gould, I968). Synergism of ribosides, like inosine, with amino acids as germinants for spores of many aerobic species (Hills, I949; Foerster \& Foster, I966) would suggest that the riboside may function, like pressure, to increase spore permeability to the amino acid as summarized in Fig. 5. At present, the 'germination site' within the spore remains unrecognized, but may be analogous to the allosteric site postulated by Woese, Vary \& Halvorson (I968).

We would like to thank Miss C. V. Martindale, Mr G. W. Cates and Mr P. R. Stephenson for valuable technical assistance.

\section{REFERENCES}

Black, S. H. \& Gerhardt, P. (I96I). Permeability of bacterial spores. I. Characterization of glucose uptake. Journal of Bacteriology 82, 743.

Clouston, J. G. \& Wills, P. A. (1969). Initiation of germination and inactivation of Bacillus pumilis spores by hydrostatic pressure. Journal of Bacteriology 97,684 .

Douglas, H. E. \& Johnson, F. H. (I95I). The influence of hydrostatic pressure and pH on the rate of lysis of Micrococcus lysodeikticus by lysozyme. Archives of Biochemistry and Biophysics 3I, 4I.

FOERSTER, H. F. \& FosTER, J. W. (I966). Response of Bacillus spores to combinations of germinative compounds. Journal of Bacteriology 9I, I 68. 
Gibss, B. M. \& HiRscel, A. (1956). Spore formation by Clostridium species in an artificial medium. Journal of Applied Bacteriology 19, 129.

Gonikberg, M. G., Prokhorova, N. I. \& El'yanov, B. S. (I968). Effect of high pressure on the stereospecificity of enzyme catalysis. Izvestiya Akademii Nauk SSSR, Ser. khim. 12, 2841.

HILLs, G. W. (1949). Chemical factors in the germination of spore-bearing aerobes. The effects of amino-acids on the germination of Bacillus anthracis, with some observations on the relation of optical form to biological activity. Biochemical Journal 45, 363 .

JoNes, A. \& Gould, G. W. (1968). Stimulation of germination of bacterial spores by analogues of D-alanine. Journal of General Microbiology 53, 383.

LAIDLER, K. J. (I95I). The influence of pressure on the rates of biological reactions. Archives of Biochemistry 30, 226.

LandaU, J. V. \& Peabody, R. A. (1963). Endogenous adenosine triphosphate levels in human amnion cells during application of high hydrostatic pressure. Experimental Cell Research 29, 54 .

RoDE, L. J. \& FosTER, J. W. (1960). Mechanical germination of bacterial spores. Proceedings of the National Academy of Sciences of the United States of America 46, 118.

Sale, A. J., Gould, G. W. \& Hamilton, W. A. (1970). Inactivation of bacterial spores by hydrostatic pressure. Journal of General Microbiology 60, 323.

WARREN, S. C. \& Gould, G. W. (I968). Bacillus cereus spore germination: absolute requirement for an amino acid. Biochimica et Biophysica Acta 170, 34I.

Werbin, H. \& MCLAREN, A. D. (195I $a$ ). The effect of high pressure on the rates of proteolytic hydrolysis I. Chymotrypsin. Archives of Biochemistry and Biophysics 3I, 285.

Werbin, H. \& MCLaRen, A. D. (I95I $b$ ). The effect of high pressure on the rates of proteolytic hydrolysis II. Trypsin. Archives of Biochemistry and Biophysics 3r, 325.

Woese, C. R., VARY, J. C. \& Halvorson, H. O. (1968). A kinetic model for bacterial spore germination. Proceedings of the National Academy of Sciences of the United States of America 59, 869.

Wood, W. A. \& GuNSALUS, I. C. (I95I). D-Alanine formation: a racemase in Streptococcus faecalis. Journal of Biological Chemistry 190, 403.

Yosнiмoto, S. (1958). The action of D-amino acid oxidase on $\epsilon$-acyllysine and lysine. Archives of Biochemistry and Biophysics 75, 280. 